\title{
Guest Editorial: Special Section on Detection
}

\author{
Stephen M. Olenick*, Combustion Science \& Engineering, Inc., Columbia, \\ $M D, U S A$
}

In March, 2008, The Fire Protection Research Foundation convened its annual Suppression and Detection Research and Applications Conference (SUPDET) in Orlando, Florida to advance the current state of suppression and detection through presentations by leaders in the fields. Nineteen papers on suppression and eighteen papers on detection were presented and discussed among the audience. The entire program of the conference including all of the submitted papers is available at the Foundation's website (www.nfpa.org/Foundation).

The following four papers constitute some of the most interesting detection presentations from the SUPDET 2008 conference. The papers were invited for inclusion in this special issue. The papers were expanded and peer-reviewed to meet the requirements of this journal. They cover a wide range of topics and demonstrate the breadth of ongoing research in the field of detection. Also of interest is the international flavor of these papers which include works of research from the United States, Canada, United Kingdom, and Australia.

The first addresses experimental work from the United States on smoke detection for ceilings containing deep beams, and has findings applicable to code development as well as computer modeling of smoke flows and smoke deposition on surfaces. The second discusses a considerable project on the detection of fires in tunnels which examined existing detection equipment for tunnels and included both computer modeling as well as experiments in both the United States and Canada. The third discusses the ability of installed fire protection detection and sensing devices in a building to aid firefighting efforts and includes experimental and modeling results of the Dalmarnock testing in the United Kingdom. The final paper was the keynote address from the detection section of the conference and outlines much of the cutting edge research in the last ten years at Victoria University in Australia on the very pertinent topic of awakening sleeping occupants.

These papers demonstrate that the international fire detection community is actively researching, through both computer modeling and experimentation, many diverse aspects of fire detection including notification and awakening, sensor-aided firefighting, and detector siting in unique geometries. Hopefully, the fire detection research community will continue to pursue and develop these topics as well as other fire detection-related topics that have practical application and result in better fire safety for the public.

\footnotetext{
* Correspondence should be addressed to: Stephen M. Olenick, E-mail: solenick@csefire.com
} 